\title{
O RITO INICIÁTICO E \\ O ROMANCE DE FORMAÇÃO: \\ UMA ANÁLISE MITOPOÉIICA DE \\ UMA HISTÓRIA COMUM
}

http://dx.doi.org/10.11606/issn.2237-1184.v0i27p43-60

\section{RESUMO}

$\mathrm{O}$ artigo discute a ligação entre o rito iniciático e o romance de formação Uma História Comum, de Ivan Aleksándrovitch Gontcharóv. A análise centra-se, principalmente, na relação do indivíduo com o tempo e a característica intergeracional da formação do protagonista.

\section{ABSTRACT}

This article discusses the relation between the initiation rite and the novel of formation Same Old Story, by Ivan Aleksandrovich Goncharov. The analysis is centers on the subject-time relation, and the intergenerational characteristic of the protagonist's formation.
Rafael Bonavina

Universidade de São Paulo (USP)

Bruno Gomide

Universidade de São Paulo (USP)

\section{PALAVRAS-CHAVE:}

Ivan Aleksándrovitch

Gontcharóv;

Uma História Comum;

Romance de Formação;

Bildungsroman;

Mito;

Rito de iniciação.

\section{KEYWORDS:}

Ivan Aleksandrovich

Goncharov;

Same Old Story;

Novel of Formation;

Bildungsroman;

Myth;

Initiation Rite. 
"Pretendeis, acaso, entrar no Paraíso, sem antes terdes de passar pelo que passaram os vossos antecessores?"

Corão 2:214

O primeiro romance de Ivan Aleksándrovitch Gontcharóv, Uma História Comum, foi publicado em 1847 e coincide, aproximadamente, com "a data do nascimento do realismo russo, chamado de o primeiro romance em prosa da Rússia. Portanto, reflete a atitude polêmica adotada pelo realismo em relação ao romantismo"1. Seria lícito dizer que nasce também o Bildungsroman russo, ou para usar a expressão autóctone, o Román Vospitániia. A esse respeito, Bakhtin afirma, categórico:

Há uma particular variedade de gêneros romanescos, que recebem o nome de "romance de formação" ("Erziehungsroman" ou "Bildungsroman"). Geralmente, aqui aparecem (em ordem cronológica) os seguintes modelos da diversidade desse gênero: "Ciropédia", de Xenofonte (antiguidade); "Parzíval", de Wolfram Von Eschenbach; "Gargantua e Pantagruel”, de Rabelais; [...] "Emílio", de Rousseau (já que há bastantes elementos de romance nesse tratado de pedagogia); "Wilhelm Meister", de Goethe (ambos romances); [...] “História Comum” e “Oblómov”, de Gontcharóv 2

O objetivo deste trabalho é demonstrar alguns pontos de contato entre o rito iniciático e o romance de formação, utilizando Uma História Comum para balizar a discussão. Começaremos pelo processo de amadurecimento "que separa o jovem sexualmente já maduro da mãe e das irmãs, do grupo de mulheres e crianças não iniciadas, e que o conduz ao grupo de homens-caçadores adultos com o posterior direito ao casamento, etc." 3 , o rito iniciático. Trata-se de uma

\footnotetext{
${ }^{1}$ EHRE, M. Oblomov and his creator. Princeton: Princeton University Press, 1973. p. 117 (tradução nossa)

2 BAKHTIN, M. K Románu Vospitánia. Sobránie Sotchinéni, tomo III. Moscou: Iazykí Slaviánskikh Kultúr, 2012. p. 327. (tradução nossa)

${ }^{3}$ MELETÍNSKI, E. Poética do Mito. Rio de Janeiro: Forense Universitária, 1987. p. 264.
}

44 | D O S S I E : ROMANCE DE FORMAÇ̃̃O - CAMINHOS E DESCAMINHOS DO HERÓI 
introdução do candidato nas técnicas, obrigações e prerrogativas de sua vocação com um radical reajustamento de sua relação emocional com as imagens parentais. O mistagogo (pai ou pai substituto) deve entregar os símbolos do ofício tão-somente ao filho que tiver sido efetivamente purgado de todas as catexes infantis impróprias ${ }^{4}$

Um breve aparte sobre os termos aqui adotados, descartaremos "pai" e "filho", pois ressoam, de imediato, certas leituras psicanalíticas, demasiadamente calcadas nas teorias jungianas, que correm o risco de se distanciarem da literatura. Também tentaremos evitar o excesso de mitologização da literatura; na falta de capacidade para melhor expressão, uso as palavras de Luís da Camara Cascudo:

Não cito as escolas meteorológica, filológica, antropológica, historista, ritualista, a infalível eclética, afora uma dúzia de cisões e cismas eruditos. Ainda não me foi concedida a sabedoria para aproximar-me dessas discussões substanciais. Um dia, querendo Deus, irei também discutir se o Jabuti representa o Sol, a força criadora da Vontade, um urmythus ou simplesmente um Jabuti. ${ }^{5}$

Aqui, os mitos são o ritual posto no papel - ou seria melhor dizer no pergaminho, na pedra? -, a cristalização de uma prática cultural. Eles "não expressam complexos latentes e arquétipos do inconsciente, mas a anatomia do intelecto; ou seja, a estrutura intelectual primordial do inconsciente" 6 . No rito iniciático, as provas consistem em resistência física, determinação, e até mesmo riscos de morte. Ao final, se bem sucedido, o iniciando não será mais visto como uma criança, mas como adulto. "Neste sentido, não se limita a uma mera instrução, no sentido clássico do termo, mas antes se trata antes de uma formação [Bildung] no sentido que a formação transforma aquele que ela visa."7 Obviamente, essa palavra alemã é a base da discussão a respeito do romance de formação (Bildungsroman).

Antes de falarmos sobre isso, comecemos com algumas considerações de Bakhtin a respeito do romance, lato sensu:

A esmagadora maioria dos romances (e variedades de romances) só conhece a imagem pronta do herói. Todos os movimentos dos romances, todas as representações dos eventos e aventuras dele movem o personagem no espaço, transportam-no nos degraus da escada da hierarquia social - de um

\footnotetext{
${ }^{4}$ CAMPBELL, J. O Herói de Mil Faces. Tradução de Adail Ubirajara Sobral. São Paulo: Pensamento, 1989. p. 133.

5 CASCUDO, L. Contos tradicionais do Brasil. Belo Horizonte: Itatiaia; São Paulo: Editora da Universidade de São Paulo, 1986. p. 20.

${ }^{6}$ MELETINSKI, E. Ot mifa k literature. Moscou: RGGU, 2001, p. 22 (tradução nossa).

7 ARAÚJO, A. "Labirinto e Iniciação. Da Natureza do Rito Iniciático do Herói".

Revista Portuguesa De Filosofia, 69(2), 309-330. Disponível em:

<https://www.jstor.org/stable/23631111> Acesso em: 21 abr. 2018. p. 320
}

45 | D O S S I Ê : ROMANCE DE FORMAÇ̃̃O - CAMINHOS E DESCAMINHOS DO HERÓI 
mendigo, ele se torna rico; de um sem-teto, um nobre -, o herói ora se afasta, ora se aproxima do seu objetivo - da noiva, da vitória, da riqueza, etc. Os acontecimentos transformam seu destino, mudam a sua posição na vida e na sociedade; mas ele mesmo, diante disso, permanece imutável, igual ao que era, o caráter dele não muda. ${ }^{8}$

Aos poucos se esquadrinha o conceito de "romance de formação": o caráter do protagonista se transforma. Como veremos, esse é o caso de Aleksandr Adúiev em Uma História Comum. No entanto, não é comum que os personagens mudem, principalmente em narrativas que cubram um longo período, digamos dez anos? Seria muito fácil considerar quase qualquer narrativa desse tipo como um romance de formação. Diz Mazzari:

Tomar o conceito de Bildungsroman de maneira sincrética, larga e abstrata pode levar a um mosaico de títulos determinado pelo princípio do anythinggoes. Trata-se afinal de um termo dotado de extraordinária força sugestiva, com a mais ampla aceitação, o qual parece corresponder plenamente a uma tendência universal e, porventura, até mesmo atemporal da literatura, isto é, pôr em cena personagens em processo de aperfeiçoamento, aprendizagem, educação, formação. ${ }^{9}$

Atemporal, com certeza, mas, talvez, não da literatura no sentido moderno da palavra, e, sim, no sentido mitológico, da representação da percepção do mundo; da literatura como narrativa. É preciso tomar o Bildungsroman em sentido estrito, senão corre-se o risco, como alerta Mazzari, de tornar inútil a nomenclatura. Em russo, o termo "vospitániie" ("formação", "educação), do qual "vospitániia" é o genitivo singular, também traz esse significado. Assim, román vospitániia pode ser entendido em semelhante chave, pois seu campo semântico não se limita à educação formal da escola, mas à transformação atrelada ao rito de iniciação, à educação intergeracional. Encerramos o aparte terminológico.

De acordo com Frye,

A forma completa do romance é claramente a da busca bemsucedida, e tal forma bem acabada possui três estágios principais: o estágio da jornada perigosa e das aventuras preliminares menores; o esforço crucial, geralmente algum tipo

\footnotetext{
${ }^{8}$ BAKHTIN, M. K Románu Vospitánia. Sobránie Sotchinéni, tomo III. Moscou: Iazykí Slaviánskikh Kultúr, 2012. p. 328. (tradução nossa)

${ }^{9}$ MAZZARI, M. Labirintos da aprendizagem: Pacto fáustico, romance de formação e outros temas de literatura comparada. São Paulo: Editora 34, 2010. p. 128.
} 
de batalha em que tanto o herói, quanto seu inimigo, ou ambos, devem morrer; e a exaltação do herói. ${ }^{10}$

A grande diferença entre o mito iniciático e o Bildungsroman é a diferença substancial dos iniciandos. "Distinguimos o mito do romance pelo poder de ação do herói: no mito propriamente dito, ele é divino; no romance propriamente dito, ele é humano."11 Embora sejam divinos, os personagens do mito não são necessariamente perfeitos e, muitas vezes, é essa a razão de se contar a história. Na mitologia de diversos povos, não são raros os pecadilhos cometidos pelos deuses: artimanhas, traições, mentiras, intrigas, etc. Na verdade, sequer seria preciso deixar o seio da mitologia judaico-cristã: em Gênesis 6:6, diz-se que o "Senhor arrependeuse de ter criado o homem na terra e teve o coração ferido de íntima dor"12. Afloram por causa da corrupção humana duas características tipicamente humanas, o arrependimento e a dor - mesmo que metafórica. São indícios de certa reciprocidade quanto à imagem e semelhança, aproximando Deus dos deuses gregos, humanizados a ponto de enganarem uns aos outros, cultivar desavenças por orgulho, recusarem-se a admitir seus erros, etc.

A perda dessa potência divina cosmogônica, que subjuga a ordem cósmica aos caprichos de uma entidade, ou a certo número delas, é uma das características mais importantes nessa transição, pois é justamente por isso que

los mitos de la creación empiezan a dar lugar a la leyenda, como en el libro del Génesis, después de la expulsión del Paraíso. Los héroes se vuelven menos y menos fabulosos, hasta que al fin, en los estadios finales de las diversas tradiciones locales, la leyenda desemboca a la luz del día del tiempo hecho crónica. ${ }^{13}$

Quanto mais avançamos no processo de antropocentrização tanto maior será a distância entre o protagonista da narrativa ficcional e a essência divina. Essa transformação da própria estrutura textual implica na mudança do processo de formação do herói, pois as características conquistadas através do rito iniciático não serão mais as mesmas. Em linhas gerais: no caso do rito iniciático, há provas de resistência à dor; no mito, a realização do humanamente impossível; no romance de formação,

\footnotetext{
${ }^{10}$ FRYE, N. Anatomia da Crítica. Tradução de Marcus de Martini. São Paulo: É Realizações, 2014. pp. 327-328.

${ }^{11}$ FRYE, N. Anatomia da Crítica. Tradução de Marcus de Martini. São Paulo: É Realizações, 2014. p. 328 .

12 BÍBLIA SAGRADA. Gênesis. Tradução pelo Centro Bíblico Católico. São Paulo: Ave Maria, 1993. p. 53.

${ }^{13}$ CHAYO, J. El mito, el rito y la literatura. Casa del Tiempo, Cidade do México, p.54-71, out. 2002. p. 61. Mensal. Disponível em:

<http://www.uam.mx/difusion/revista/oct2002/asse.pdf>. Acesso em: 21 abr. 2018
}

47 | D O S S I E : ROMANCE DE FORMAÇ̃̃O - CAMINHOS E DESCAMINHOS DO HERÓI 
as provas não são físicas, deve-se resistir às provações emocionais, espirituais, intelectuais. Então, paulatinamente, a experiência do amadurecimento torna-se muito menos objetiva, material, corporal e mais subjetiva, espiritual, intangível.

Um rito iniciático malsucedido pode causar graves ferimentos, mutilações e até a morte. No mito, esse fracasso pode ter consequências ainda piores, graças à natureza sobrenatural dos envolvidos. Como exemplo, peguemos o mito de Faetonte: por causa de um mistagogo ninguém menos do que Hélio - impaciente, por assim dizer, sua iniciação é turbulenta e repentina, portanto malsucedida. Como consequência, ele não é capaz de ocupar a posição do seu mestre; ao conduzir a carruagem do Sol pelos céus, Faetonte perde o controle, voando ora baixo demais, ora muito alto, assim, causa danos horríveis à ordem cósmica, queima os céus e a Terra. Para impedir que o dano seja ainda maior, Zeus abate Faetonte com um raio. A má formação do protagonista do Bildungsroman raramente tem consequências para o cosmos, pois ele seria incapaz de fazê-lo. É mais comum encontrarmos consequências que afetem a vida do próprio iniciando e, talvez, das pessoas à sua volta.

Embora isso ilumine um ponto na escuridão, a luz revela, na penumbra, uma pergunta tenebrosa: e como o rito iniciático tornou-se o romance de formação? A resposta é difícil em um espaço tão curto, pois se trata de um processo milenar. Felizmente, não estamos sozinhos a tatear no escuro, podemos contar com diversos guias - quiçá mistagogos nossos - para essa jornada crítica. Para discutir essa transformação, em primeiro lugar, é preciso considerar que a concepção de mundo do homem oitocentista é muito diferente da percepção primitiva. Como exemplo, pensemos no tempo; ele era observável, percebido em ciclos: as estações naturais, os dias e noites, as cerimônias. Diz Bakhtin:

Este tempo é coletivo, ele se diferencia e é medido apenas pelos acontecimentos da vida coletiva. Tudo o que nele existe, existe somente para o coletivo. A série individual da existência ainda não tinha se destacado (o tempo interior da vida individual ainda não existe, o indivíduo vive totalmente do lado de fora, num todo coletivo). [...] É o tempo do crescimento produtivo. É o tempo da vida vegetativa, da floração, da fecundidade, da maturação, da multiplicação dos frutos, da proliferação. ${ }^{14}$

Como veremos adiante, em Uma História Comum, a repetição do tempo não é observável na natureza; ela é interiorizada, pessoal, foi engolida pelo indivíduo e agora faz parte dele. O caráter cíclico está justamente em haver uma recorrência na trajetória de vida dos personagens, há uma constante troca de papeis entre diferentes indivíduos

${ }^{14}$ BAKHTIN, M. Questões de Literatura e de Estética: A Teoria do Romance. São Paulo, Hucitec, 1990. p. 317.

48 | D O S S I Ê : ROMANCE DE FORMAÇ̃̃O - CAMINHOS E DESCAMINHOS DO HERÓI 
dentro de determinada sociedade, a natural sucessão das gerações, o passar do bastão.

O tempo não é a única diferença entre o mito e a literatura.

o mito é antipsicológico e não se ocupa em absoluto dos destinos de indivíduos isolados. Isso é perfeitamente natural para uma sociedade psicológica e socialmente homogênea, na qual, tanto na vida real quanto na consciência dos indivíduos, o princípio do clã predomina decisivamente sobre o individual e por isso a coletividade coíbe com relativa facilidade qualquer rebeldia individual. ${ }^{15}$

Conforme Mazzari nos advertiu, a característica principal de um Bildungsroman é mostrar a maturação de um personagem; o que o faz ser, nesse sentido, absolutamente oposto ao mito. Mesmo que se fale metonimicamente sobre o desenvolvimento de todos nós, mesmo que as constantes desilusões do protagonista possam ser consideradas como punições causadas pela "rebeldia individual", o romance não deixaria de descrever um trajeto individualizado.

À medida que o corpo social se divide em classes, o complexo sofre importantes modificações, e os motivos e temas correspondentes passam por reinterpretações. Ocorre a diferenciação gradual das esferas ideológicas. O culto separa-se da produção agrícola; a esfera do consumo isola-se e, até um certo grau, se individualiza. Os membros do complexo sofrem uma desintegração e uma transformação internas. Tais membros da vizinhança, como a comida, a bebida, o ato sexual, a morte, recuam para a vida quotidiana, que já se individualiza. ${ }^{16}$

A crescente fragmentação da percepção influencia diretamente na forma da narrativa mitológica: gradualmente, ela perde espaço, dá lugar ao conto e se transforma no romance. Por discutirmos um romance de formação do século XIX e a base estar muito distante, escolhemos um intermediário: o Conto do Graal, de Chrétien de Troyes, pois é "a partir da Idade Média que as provações da iniciação são vistas como uma das fontes do assim chamado 'romance de formação'; a própria 'iniciação', nesses romances, era um equivalente sui generis e uma herdeira da iniciação arcaica"17. Não se trata da escolha arbitrária de um herói medievo, pois são bastantes e várias as semelhanças entre Perceval e Aleksandr Adúiev: ambos são provincianos e, por não conhecerem bem a vida em sociedade, tropeçam nas quinas dos tapetes da etiqueta; são criados apenas pela mãe,

\footnotetext{
${ }^{15}$ MELETÍNSKI, E. Poética do Mito. Rio de Janeiro: Forense Universitária, 1987. pp. 263-264

16 BAKHTIN, M. Questões de Literatura e de Estética: A Teoria do Romance. São Paulo, Hucitec, 1990. p.321

${ }_{17}$ MELETÍNSKI, E. Os Arquétipos Literários; tradução Aurora Fornoni Bernardini, Homero Freitas de Andrade, Arlete Cavaliere. Cotia: Ateliê Editorial, 2015. p. 57-58.
} 
no caso de Perceval ela também desempenha o papel de mistagogo incapaz e, por isso, o cavaleiro tem a uma iniciação falha. Aliás nos dois romances há "a mãe que mantém junto a si o filho em crescimento que deseja seguir seu próprio caminho" 18 .

A história de Perceval é uma sequência de erros que "conferem verossimilhança ao processo educativo, demonstrando que Perceval não se transformou de repente" 19 , que ele é uma representação do ser humano. Ele erra por respeitar cegamente, sem muita reflexão, as diretrizes que lhe são dadas pelos diversos mistagogos espalhados por sua jornada. Diz Fernandes, "a trajetória do herói pode ser descrita justamente como a lenta percepção do verdadeiro significado dos ensinamentos ministrados" 20 . Isso também pode ser dito de Aleksandr Adúiev, pois, assim que o jovem chega à capital, o tio o aconselha de diversas maneiras, mas ele não dá ouvidos.

Esta descoberta, uma verdadeira revelação, significa que o conhecimento de sua missão é o que permite ao jovem tomar consciência da própria identidade. Conclui-se, portanto, que o objetivo da educação de Perceval é duplo: permitir a solução da aventura do Graal, o que significa, ao mesmo tempo, oferecer condições para a aquisição da autoconsciência. Sendo que o processo ocorre de forma aparentemente casual mas sequenciada, parece haver um plano oculto predeterminado para o percurso do herói: com efeito, a educação de Perceval é fruto de um chamado misterioso, uma vocação. ${ }^{21}$

A autoconsciência é uma das características do desenvolvimento do protagonista do romance de formação. No caso de Perceval, ela se dá através da súbita descoberta do próprio nome; pouco antes da morte de sua mãe, Aleksandr percebe sua própria condição e sua (falta de) inserção na sociedade oitocentista. Em ambos os casos, seria possível falar em súbita tomada de consciência a respeito do próprio lugar no mundo; em uma palavra, epifania. No universo dos fidalgos, o nome do indivíduo é equivalente à função desempenhada pelo homem russo no século XIX, ou seja, diz quem é aquela pessoa, qual nicho social ela ocupa.

O romance de Troyes compartilha o motivo "chamado do Destino" com o conto folclórico de Iliá Múromets, o bogatýr - espécie de cavaleiro do folclore russo - de força inacreditável.

18 CAMPBELL, J. O Herói de Mil Faces. Tradução de Adail Ubirajara Sobral. São Paulo: Pensamento, 1989. p. 112.

${ }^{19}$ FERNANDES, R. "A formação do cavaleiro: Perceval ou O Conto do Graal". Mirabilia, [s. L.], p.127-140, 2004. Disponível em:

<http://www.revistamirabilia.com/sites/default/files/pdfs/2004_10.pdf>. Acesso em: 01/05/2018. p. 132

20 Ibid. p. 133

${ }^{21}$ Ibid. p. 134.

50 | D O S S I Ê : ROMANCE DE FORMAÇ̃̃O - CAMINHOS E DESCAMINHOS DO HERÓI 
Na então famosa vila de Múrom, nas terras de Karatcharov, vivia o camponês Ivan Timofiêevitch. Ele tinha um filho amado, Iliá Múromets, que ficou deitado por trinta anos e, quando passou dos trinta, ele começou a andar a passos firmes, sentiu em si uma força imensa, forjou sua armadura e uma lança de aço, e montou em seu bom cavalo de bogatýr. ${ }^{22}$

Nessa versão, Iliá simplesmente levanta depois de trinta anos, mas há variações em que curandeiros ou viajantes o visitam e lhe concedem o dom da força imensa (síla velíkaia), ora usando rezas poderosas, ora benzendo a água que ele bebe. Munido de seu equipamento, Iliá pede a bênção aos pais para "rezar para Deus na magnífica cidade de Kíev e curvar-me para o príncipe"23, esse caberia, com alguma roupagem ocidental, no papel do Rei Artur. Por não ouvir os avisos dos seus pais, Iliá tem de provar sua força contra outro ser de poder sobre-humano, o Rouxinol-Assassino, cujo assovio é mortal.

Façamos uma justaposição de quatro personagens: Faetonte, Iliá Múromets, Perceval e Aleksandr Adúiev. Prestemos atenção à desmitologização da narrativa: Faetonte voa pelos céus em uma carruagem de fogo vestindo a coroa do Sol, trazendo o dia e a luz para o mundo; Iliá Múromets sobrevive ao assovio mortal do Rouxinol-Assassino e o derrota; Perceval vence o Cavaleiro Vermelho; Aleksandr Adúiev torna-se adulto. A cada passo, diminui o poder sobre-humano do protagonista até chegarmos à representação de uma pessoa comum, suas conquistas deixam de ser grandiosas e passam a ser prosaicas; por vezes, como em $O$ Capote, até mesmo mesquinhas.

Na mesma medida que diminui o poder desses heróis, cresce a sua profundidade interior. Enquanto a iniciação de Iliá Múromets tem, no máximo, uma página e as primeiras aventuras de Perceval já somem algumas folhas, a formação de Aleksandr é o próprio livro. A diferença é ululante. Embora o potencial do herói oitocentista seja muito menos maravilhoso, sua substância é muito mais psicológica, humana, enfim, moderna. Dificilmente alguém, em sã consciência, acreditaria ser Múromets; por outro lado, é totalmente plausível para o leitor contemporâneo e brasileiro projetar a própria vida na trajetória de Aleksandr, apesar da distância cronológica, geográfica e cultural.

Nesse crescendo romanesco; melhor, nesse mergulho às profundezas da representação da alma humana, o surgimento do Bildungsroman faz eco a uma das mais profundas crises culturais da Europa Ocidental.

when status society starts to collapse, the countryside is abandoned for the city, and the world of work changes at an incredible and incessant pace, the

\footnotetext{
22 AFANÁSSIEV, A. Rússkiie Naródnye Skázki. Moscou: Sovremménik, 1988. p. 373.

${ }^{23}$ Ibid. p. 373.
}

51 | D O S S I E : ROMANCE DE FORMAÇ̃̃O - CAMINHOS E DESCAMINHOS DO HERÓI 
colourless and uneventful socialization of 'old' youth becomes increasingly implausible: it becomes a problem, one that makes youth itself problematic ${ }^{24}$

Esse êxodo rural implica na mudança da estrutura social e da visão de mundo do homem citadino, principalmente o metropolitano. Em Uma História Comum, isso transparece com clareza meridiana, nas palavras de Ehre, "a oposição entre o racionalismo impessoal do tio e a defesa do sentimento e da afeição familiar do sobrinho também reflete um antagonismo entre a sociedade burocrática europeizada da capital e a aristocracia rural mais tradicional." 25 Embora esse fenômeno não seja exclusividade da época, há sensível diferença quantitativa no período da Revolução Industrial. Nesse momento de modernização do trabalho, de desenvolvimento da literatura e da cultura russas, surge esse romance.

Como símbolos, o mito e o Bildungsroman voltam a se aproximar. Meletínski afirma que, para o romantismo alemão, "o mito é um fenômeno estético, um modelo da obra de arte, tem um sentido simbólico" 26 . Semelhante é o caso do romance de formação. Eles são símbolos de suas épocas, nascidos da visão de mundo que lhes deu origem. Não pode ser gratuito que, perto do lançamento dos Anos de Aprendizado de Wilhelm Meister, outras ocorrências tenham aparecido por toda a Europa. É possível, sim, falar do nascimento de um modelo literário que passou a ser reproduzido, mas há outra possibilidade, igualmente interessante, para a divulgação do romance de formação.

For Cassirer, and Panofsky, through such a form 'a particular spiritual content [here, a specific image of modernity] is connected to a specific material sign [here, youth] and intimately identified with it. 'A specific image of modernity': the image conveyed precisely by the 'youthful' attributes of mobility and inner restlessness. Modernity as a bewitching and risky process full of 'great expectations' and 'lost illusions'27

Então, no Bildungsroman, o jovem é a imagem arquetípica por ser composto por aquelas "catexes infantis" a serem expurgadas pelo rito de iniciação, bem como as chagas da modernidade. Em certo momento, Aleksandr Adúiev se questiona: "não seria uma lei geral da natureza que a juventude deva ser ansiosa, turbulenta, por vezes estranho, tola, e que quaisquer sonhos acalmem-se com o tempo, como se acalmaram os meus?" 28, tomando consciência de sua própria trajetória, do seu papel de

\footnotetext{
${ }^{24}$ MORETTI, F. The way of the world: the Bildungsroman in European culture. Thetford: Verso, 1987. p. 4-5.

${ }^{25}$ EHRE, M. Oblomov and his creator. Princeton: Princeton University Press, 1973, p. 137.

${ }^{26}$ MELETINSKI, E. Ot mifa k literature. Moscou: RGGU, 2001. p.12 (tradução nossa)

27 Op. cit. p. 5.

28 GONTCHARÓV, I. Sobránie Sotchiniéni v vosmí tomákh, tomo I. Moscou: khudójestvennaia literatúra, 1977. p. 318. (tradução nossa)
}

52 | D O S S I Ê : ROMANCE DE FORMAÇ̃̃O - CAMINHOS E DESCAMINHOS DO HERÓI 
iniciando e, sem saber, representando muito bem essa imagem da modernidade. Se o romance de formação é um fenômeno literário central, o jovem,

therefore, achieves its symbolic centrality, and the 'great narrative' of the Bildungsroman comes into being, this is because Europe has to attach a meaning, not so much to youth, as to modernity. ${ }^{29}$

Essa transformação não poderia deixar de significar uma nova forma de representação do mundo, de percepção, de romance e, portanto, de iniciação, já que também mudaram as características do indivíduo plenamente formado. Embora o rito iniciático exista em Uma História Comum e seja tomado como algo absolutamente natural, imutável e eterno pelo protagonista Aleksandr Adúiev, não se trata de um fato humano estanque, justamente o contrário, como pretendíamos demonstrar, é o resultado de um processo lento e gradativo de desmitologização.

\section{A História de Sempre}

Talvez uma das melhores traduções para o inglês de Obyknoviénnaia Istóriia tenha sido encontrada por Stephen Pearl, que chamou a sua versão de The Same Old Story. Ele acerta em cheio o tom do romance. Aqui, optamos por Uma História Comum, na tentativa de preservar o jogo linguístico com o título do livro sobre o, suposto, plágio de Ivan Turguênev, Neobyknoviénnaia Istóriia, Uma História Incomum. Descartamos o par História Ordinária - História Extraordinária que, apesar de manter o jogo e caber bem no segundo, dá ao primeiro título um sentido pejorativo. Outras opções, como Aquela Velha História, A História de Sempre foram igualmente descartadas para facilitar a busca, já que não há, ainda, uma tradução consagrada em língua portuguesa. De qualquer forma, como o romance é pouco conhecido, faz-se necessário dizer duas palavras sobre a história em si.

O romance começa com Aleksandr Adúiev no interior do país, na casa de sua mãe. Ele se prepara para a viagem à capital, Petersburgo. Vale lembrar que, nos termos vistos anteriormente, isso pode ser visto como um tipo de iniciação, que

começa por um acto de rutura: a criança ou o adolescente é separado da mâe, e esta separaçâo faz-se, por vezes, de um modo bastante brutal. [...] Por outras palavras, o noviço deve abandonar para sempre o mundo infantil,

\footnotetext{
${ }^{29}$ MORETTI, F. The way of the world: the Bildungsroman in European culture. Thetford: Verso, 1987. p. 4-5.
} 
com a irresponsabilidade que o acompanha, para aceder a uma existência superior, isto é, aquela enriquecida com a tradiçâo mítica da tribo ${ }^{30}$

Como as "catexes infantis" a serem abandonadas pelo iniciando estão ligadas aos valores rurais, a casa no interior representa o papel de "mundo infantil" conforme descrito acima. Apesar das súplicas e apelos sentimentais da mãe, Aleksandr vence o primeiro obstáculo de sua trajetória e vai para Petersburgo visitar o seu tio, Piotr Adúiev, que será seu mistagogo.

Ao se encontrarem pela primeira vez, travam uma conversa para se conhecerem melhor. Aleksandr derrama os sonhos juvenis a respeito de Petersburgo, Piotr faz a barba e faz caretas para o espelho enquanto escuta. $\mathrm{O}$ tio pergunta-lhe a razão de vir à capital. Abismado, em primeiro momento, o jovem responde: "jit"; em russo os verbos "viver" e "morar" são expressos por essa palavra. Então, ao mesmo tempo, diz o iniciando que veio para morar em Petersburgo e para viver, talvez, em sentido metafórico. Depois de uma breve discussão, o mistagogo repete a pergunta, eis como segue a conversa.

- Para realizar esses sonhos que povoam...

- Você não seria de escrever versos? - perguntou de repente Piotr Ivanytch.

- E prosa também, titio; quer que eu traga?

- Não, não!.. fica para uma próxima; eu só perguntei.

- E então?

- É que você fala de um jeito...

- É ruim?

- Não, é muito bom, e estranho. ${ }^{31}$

Pela primeira vez, aparece o problema da forma de falar, tema recorrente ao longo da obra. Aleksandr diz que seu professor de estética falava dessa maneira. $O$ tio pede que ele não imite o professor de estética da escola, mas fale de modo mais simples, como todo mundo. Afirma Ehre, "o romance é, em certo nível, uma lição de linguagem. O sobrinho tornase o seu tio por abandonar a sua própria linguagem e adotar a do outro" 32 . Piotr diz isso textualmente: "antes de qualquer coisa, esqueça todos esses sentimentos sagrados e celestiais, e acostume-se às coisas assim como elas

\footnotetext{
${ }^{30}$ ARAÚJO, A. “Labirinto e Iniciação. Da Natureza do Rito Iniciático do Herói”. Revista Portuguesa De Filosofia, 69(2), 309-330, p. 319. Disponível em: <https://www.jstor.org/stable/23631111> Acesso em: 21 abr. 2018

31 GONTCHARÓV, I. Sobránie Sotchinieni v vosmí tomákh, tomo I. Moscou: khudójestvennaia literatúra, 1977, p. 69. (tradução nossa)

32 EHRE, Milton. Oblomov and his creator. Princeton: Princeton University Press, 1973, p. 121
}

54 | D O S S I Ê : ROMANCE DE FORMAÇ̃̃O - CAMINHOS E DESCAMINHOS DO HERÓI 
são, mais simples; seria melhor e você falaria mais claramente". 33 Aos poucos, os arroubos líricos de Aleksandr são trocados pelo sarcasmo.

Como o modo de se expressar é um reflexo do próprio indivíduo, do seu âmago, essa mudança não implica em mero abandono das palavras e, sim, dos campos semânticos implícitos nessas palavras. A troca de linguagem é um símbolo com muitas possíveis interpretações: a troca do romantismo pelo realismo; o êxodo do campo para cidade; a mudança dos valores tradicionais russos pelo cosmopolitismo de São Petersburgo, a "janela para a Europa”, como a cidade era chamada, e assim por diante.

Tomemos Wilheim como protagonista-modelo, já que seu romance é um marco do romance de formação oitocentista, embora não seja a primeira narrativa de formação. "Se, portanto, os anos de aprendizagem de Wilhelm Meister confluem para um final feliz, este consiste precisamente na efetiva conscientização, por parte do herói, da necessidade de estabelecer limites à aspiração individualista e incondicional". 34 Infelizmente para o iniciando, isso não ocorre de imediato, demora alguns anos no caso dos Adúiev; sabendo disso, por experiência própria, o tio lamenta:

Isso não importa, talvez você seja dez vezes mais inteligente e melhor do que eu... é, parece que você não tem uma natureza que se entregue à nova ordem; e a velha - minha nossa! Por exemplo, você foi paparicado e mimado pela mãe; você aguentaria tudo o que eu passei? Você deve ser um sonhador, e aqui não dá tempo de sonhar; os do nosso tipo vêm para cá para fazer negócios. ${ }^{35}$

Ele está resumindo o problema para o sobrinho, que, obviamente, não dará ouvidos às palavras do seu mistagogo, ou melhor, não entenderá o que isso significa, assim como Perceval não compreendeu. Em outras palavras, o tio diz: você deve abandonar essa antiga ordem e aderir à nova, andar pari passu com os nossos tempos, ombro a ombro com os contemporâneos. Ainda, já reforçando sua ironia característica, diz que ser mais inteligente, ou melhor, não importa, interessa, sim, é aprender a "fazer negócios" (diélo diélat').

Já que as palavras não foram aladas, vejamos como acontece o aprendizado. Do interior, o jovem trouxe alguns objetos consigo. Uma mecha de cabelo e um anel de sua amada, alguns versos e guloseimas. A mecha e o anel são jogados pela janela pelo tio, assim que os vê. Depois de ridicularizados, os versos são usados para acender um charuto. Em

\footnotetext{
${ }^{33}$ Ibid. p. 71. (tradução nossa)

${ }^{34}$ MAZZARI, M. Labirintos da aprendizagem: Pacto fáustico, romance de formação e outros temas de literatura comparada. São Paulo: 34, 2010. p.114

35 GONTCHARÓV, I. Sobránie Sotchiniéni v vosmí tomákh, tomo I. Moscou: khudójestvennaia literatúra, 1977. p. 70. (tradução nossa)
}

55 | D O S S I Ê : ROMANCE DE FORMAÇ̃̃O - CAMINHOS E DESCAMINHOS DO HERÓI 
brevíssimo aparte sobre a ironia gontcharoviana, os versos de Aleksandr são, na verdade, trechos de um poema escrito pelo próprio Gontcharóv antes de abandonar a escrita de poesia. Então existe, aqui, uma camada auto-irônica sobre a tonalidade romântica da própria poesia juvenil. Retomemos. Depois vem um amor, uma decepção amorosa. $\mathrm{O}$ iniciando busca alguma forma de se distrair. O tio percebe sua facilidade com as palavras e descobre como começar sua introdução na vida adulta petersburguesa: um serviço de tradução. Imediatamente Aleksandr fica empolgado, mas isso também se prova prosaico demais para a poética juventude do sobrinho: é a tradução de um artigo alemão sobre batatas.

Embora para nós, leitores, seja um espetáculo, talvez tragicômico, o aprendizado do jovem Adúiev é amargo e duro. Depois de várias provações, e pouco antes da sua epifania, Aleksandr resmunga sobre o tratamento recebido do tio.

- Nada. Queria me provocar! Chamou-me de tolo! Queria brincar comigo, como uma bolinha, é um insulto! Não se é jovem pra sempre. A escola que passei serviu para alguma coisa. Como o senhor me passou um sermão! Acha que eu sou cego? O senhor só fez um truque, mas eu percebi. ${ }^{36}$

A escola (Chkóla) a que Aleksandr se refere é o método de ensino que seu tio aplicara, a constante e ininterrupta deflação das expansões linguísticas, dos arroubos líricos do sobrinho. No entanto, ao herói do Bildungsroman

não basta que ele percorra um determinado desenvolvimento como se fosse um processo natural de crescimento; muito mais do que isso, ele tem de conscientizar-se expressamente de seu papel como indivíduo que se constitui na busca. Decorre daí que esse jovem, a exemplo de Wilhelm Meister, sinta-se compelido, nas diversas fases de seu desenvolvimento, a "passar em revista sua própria história" 37

Isso acontecerá posteriormente no romance. Já desiludido e cansado da vida na capital, Aleksandr volta para o campo e tenta retomar sua vida simples. No entanto, algo estava diferente. A província, em si, não havia mudado, pois há muito tempo ela que não muda, como exemplo, uma das cartas recebidas por Piotr vindas do interior é descrita desta maneira: "Era idêntica a um grande alfarrábio eslavo: trocaram a letra B por um traço com duas cruzes em cima e em baixo, e a letra K eram dois traços; escrita sem pontuação" 38 . Vale lembrar que a pontuação começa a ser amplamente

${ }^{36}$ GONTCHARÓV, I. Sobránie Sotchiniéni v vosmí tomákh, tomo I. Moscou: khudójestvennaia literatúra, 1977. p. 252. (tradução nossa)

37 Apud JACOBS; MAZZARI, Labirintos da aprendizagem: Pacto fáustico, romance de formação e outros temas de literatura comparada. São Paulo: Editora 34, 2010. p.123.

38 Ibid. p. 56. (tradução nossa)

56 | D O S S I Ê : ROMANCE DE FORMAÇ̃̃O - CAMINHOS E DESCAMINHOS DO HERÓI 
utilizada a partir do século XVII. Com isso a carta provinciana indica para a manutenção de uma prática abandonada há séculos. Quem mudou foi Aleksandr. Ele passeia pelos campos, vai à floresta, flana pelas propriedades da família sem rumo certo. Em dado momento, ele se pergunta:

E o que estou fazendo aqui? [...] definho a troco de quê? Para que desperdiço os meus talentos? Por que não brilhar lá com os meus trabalhos? Agora eu estou ficando mais racional. Em que o titio é melhor do que eu? Eu realmente não conseguiria encontrar o meu caminho? Então, até agora eu não consegui, não fiz o que me cabia - e daí? Agora acordei: é hora, é hora! 39

Essa série de perguntas o leva à aporia e, depois, à epifania: Aleksandr decide voltar para São Petersburgo. A única coisa que o impede é a mãe. Agora ela cumpre o seu papel de mãe que impede a saída do filhoherói, mas é por pouco tempo, falece pouco depois. Em seguida, Aleksandr volta à capital.

Até os personagens percebem o amadurecimento de Aleksandr. No epílogo do romance, anos depois, Piotr o elogia por suas conquistas.

- É melhor falarmos de você, - disse ele - parece que você está seguindo os meus passos...

- Quem dera, titio! - cortou Aleksandr.

- Sim! - continuou Piotr Ivanytch, - aos trinta e poucos anos já é conselheiro colegiado, um bom serviço no Estado, ganha um bom dinheiro por fora e ainda está para se casar com uma moça rica... É, os Adúievs fizeram os seus negócios! Você é como eu, só faltam as dores na lombar...

- É, às vezes eu as tenho... - disse Aleksandr, esfregando as costas. ${ }^{40}$

De um jovem poeta sonhador, cheio de arroubos líricos e rompantes emocionais para um conselheiro colegiado casado com "uma moça rica". Não é à toa que nem todos os personagens tomem isso como algo absolutamente positivo. Pouco antes dessa conversa com o tio, o maduro Aleksandr fala com sua tia, Lizaviéta Adúieva, que mostrará claramente a diferença desse novo sobrinho. Ela se lembra melancolicamente de como ele era diferente.

- Não, não sonhava. Então, o senhor entendia, explicava a vida; era, então, magnífico, nobre, inteligente... Por que não ficou daquele jeito? Por que isso foi só nas palavras, no papel, e não de verdade? Essa bondade apagou, como o Sol por trás das nuvens, de repente...

- A senhora quer dizer, ma tante, que agora eu... não sou inteligente e... não sou nobre...

39 GONTCHARÓV, I. Sobránie Sotchiniéni v vosmí tomákh, tomo I. Moscou: khudójestvennaia literatúra, 1977. p. 314 (tradução nossa)

${ }^{40}$ Ibid. p. 334. (tradução nossa)

57 | D O S S I Ê : ROMANCE DE FORMAÇ̃̃O - CAMINHOS E DESCAMINHOS DO HERÓI 
- Deus me livre! Não! Mas agora é inteligente e nobre... de um jeito diferente, não do meu jeito...

- O que fazer, ma tante? - disse Aleksandr, com um grande suspiro, os tempos são esses. Eu ando de acordo com o tempo: não dá para perder o pé! Aí eu concordo com o titio, faço minhas as palavras dele... ${ }^{41}$

Nota-se que Gontcharóv retratou um tipo de desilusão, de amadurecimento amargo. Antes, Aleksandr era adorado pela tia por sua sinceridade, afetividade, espontaneidade; agora, ela mal o reconhece. Como diz Bakhtin, o ciclo de Aleksandr se fecha, revela-se um

tipo de ciclo de formação, que mantém a ligação (apesar de não ser tão próxima) com o crescimento, representa certo caminho, reiterado continuamente, da formação do homem do jovem idealista e sonhador à visível sobriedade e praticidade. [...] Para esse tipo de romance de formação é característica a representação do mundo e da vida como uma experiência, como uma escola, pela qual o homem deve atravessar e levar dela só um resultado: a sobriedade com maior ou menor grau de resignação. ${ }^{42}$

Como vimos anteriormente, Aleksandr usa o mesmo termo que Bakhtin para se referir ao processo de aprendizagem, "escola" (chkóla). Não bastasse essa mudança de jovem sonhador a adulto prático e irônico, Gontcharóv demonstra como Piotr também passa por uma transformação, atravessa sua própria "escola". Ao final do romance, ele "amolece", ele encontra um ponto médio entre os extremos da irônica praticidade e do sentimentalismo exacerbado. Ele pensa em falar sobre isso com o sobrinho, mas hesita e deixa que ele descubra sozinho. A principal ação do livro é a transformação do jovem em adulto, o sucesso da iniciação, mas há uma peripécia cômica: em certa medida, o tio e o sobrinho trocam de papeis.

Nesse cenário, é "natural que o Tempo, como fenômeno (e não a sua forma histórica, social), venha ao primeiro plano em Uma História Comum; e, de fato, o Tempo torna-se um componente de organização da queda do protagonista e, consequentemente, o enredo do romance" ${ }^{\prime \prime}$, afinal a própria estrutura do romance assemelha-se ao maior símbolo temporal desde a sua invenção, a ampulheta. De acordo com Forster, um romance em formato de ampulheta, como Thaïs, de Anatole France, é definido desta forma:

41 GONTCHARÓV, I. Sobránie Sotchiniéni v vosmí tomákh, tomo I. Moscou: khudójestvennaia literatúra, 1977. p. 334 (tradução nossa)

42BAKHTIN, M. K Románu Vospitánia. Sobránie Sotchinéni, tomo III. Moscou: Iazykí Slaviánskikh Kultúr, 2012. p. 330. (tradução nossa)

${ }^{43}$ KRASNOSCHIÓKOVA, E. A. I. A. Gontcharóv: Bildungsromán na rússkoi pótchvie. In: JDÁNOVA, M. B.; LOBKARIÓVA, A. V.; SMIRNÓVA, I. V. (Org.). Materiály mejdunaródnoi konfieriéntsii, posviaschiónnoi 190-létiiu so dnia rojdiénia I. A. Gontcharóva: Sbórnik rússkikh i zarubiéjnykh ávtorov. Uliánovsk: Korporátsia Tekhnológi Prodvijiéniia, 2003. p 10. (tradução nossa) 
dois personagens principais, Paphnuce, o asceta, e Thaïs, a cortesã. Paphnuce vive a salvo e feliz no deserto quando o livro se inicia. Thaïs leva uma vida devassa em Alexandria, e o dever dele é salvá-la. Na cena central do livro, eles se aproximam, e ele cumpre sua tarefa; ela entra num mosteiro e recebe a salvação, porque o conheceu, mas ele, porque a conheceu, recebe a danação. Os dois personagens convergem, cruzam-se e retrocedem com precisão matemática, o que é parte do prazer que o livro nos dá. ${ }^{44}$

Trocando em miúdos, o papel de "absolvido", desempenhado por Thaïs, é o de Piotr Adúiev, pois ele é retirado do extremo da racionalidade, do cinismo, para uma posição mais intermediária, sentimental. Já o papel de "condenado", representado por Paphnuce, poderia ser dado ao Aleksandr que se torna amargo, se contamina, chega a ridicularizar o amor juvenil de Piotr, cujo mote é uma flor. Esse acontecimento é paralelo à ironia do tio sobre o amor de Aleksandr; eles trocam de papeis nessas duas cenas: o ridículo tornou-se ridente e a recíproca é verdadeira. Fecha-se, assim, um ciclo.

\section{Considerações finais}

Em Uma História Comum, o autor trata o tema da substituição de gerações com seu típico sorriso de canto de boca. Seu "julgamento 'incompleto' de Aleksandr e a revelação na vida de Piotr da 'eterna ironia' da existência demonstram a profunda (e é lícito dizer, goethiana!) sabedoria de Gontcharóv, que explora a vida em toda a sua complexidade e mutabilidade dialética" 45 . Além de o tema ser extremamente importante à modernidade, no ensaio sobre sua própria obra, Antes Tarde do que Nunca (Lútchie Pózdno tchiem Nikogdá), Ivan Aleksandrovitch Gontcharóv afirma:

vejo não três romances, mas um. Todos eles estão ligados por um traço comum, uma ideia sistemática: a passagem de uma época da vida russa, que eu vivi, à outra 46

O próprio autor percebia que sua obra é marcada pela unicidade, circularidade, pelo paralelismo e, portanto, pela mímese do tempo mítico, chamada de "mutabilidade dialética" por Krasnoschiókova. Em Uma História Comum, encontra-se o reflexo da crescente desmitologização da

${ }^{44}$ FORSTER, E. Aspectos do Romance. São Paulo: Globo, 2005. p. 162.

${ }^{45}$ KRASNOSCHIÓKOVA, E. A. I. A. Gontcharóv: Bildungsromán na rússkoi pótchvie. In: JDÁNOVA, M. B.; LOBKARIÓVA, A. V.; SMIRNÓVA, I. V. (Org.). Materiály mejdunaródnoi konfieriéntsii, posviaschiónnoi 190-létiiu so dnia rojdiénia I. A. Gontcharóva: Sbórnik rússkikh i zarubiéjnykh ávtorov. Uliánovsk: Korporátsia Tekhnológi Prodvijiéniia, 2003. p. 18. (tradução nossa)

${ }^{46}$ GONTCHARÓV, I. Sobránie Sotchiniéni v vosmí tomákh, tomo VIII. Moscou: khudójestvennaia literatúra, 1977. p. 107 (tradução nossa)

59 | D O S S I Ê : ROMANCE DE FORMAÇ̃̃O - CAMINHOS E DESCAMINHOS DO HERÓI 
percepção humana do tempo; ele foi engolido pela humanidade, e ela passa a ser o metrônomo da circularidade. Em outras palavras, a passagem não é mais pautada por eclipses, verões, colheitas; ela é marcada por gerações, pelas ascensões e destronamentos, por personagens que passam as suas máscaras uns aos outros: agora, o tio ri do amor ingênuo do sobrinho; depois, Aleksandr ri da inocência do jovem Piotr; mais tarde, outro rirá de Aleksandr; etc. ad nauseam.

Assim, por trás da tessitura do romance, surge o personagem oculto a que se refere Krasnoschiókova. De fato, o Tempo é um personagem; aliás, o único personagem cuja máscara não pode ser vestida por outro. Relembremos o mito de Faetonte, o jovem herói que tentou conduzir a carruagem de Hélios e acabou por chamuscar o céu e a terra. Depois de tantas diluições da potência mítica de Faetonte, não há qualquer esperança de um personagem de Uma História Comum ser capaz de semelhante feito.

Rafael Bonavina é graduando em Letras com dupla habilitação em Português e russo pela Universidade de São Paulo. Contato: rafaelbonavina@gmail.com

Bruno Gomide é doutor em História Literária pela Unicamp e professor livre-docente de Literatura e Cultura Russa na Universidade de São Paulo. Contato: bgomide@hotmail.com 